\title{
SISTEM INFORMASI PENJUALAN SNACK BERBASIS E-COMMERCE PADA TOKO MORNING CHOCOLATE
}

\author{
Reynardo $^{1)}$, Lauw Li Hin ${ }^{2)}$ \\ ${ }^{1}$ Sistem Informasi, Fakultas Teknologi Informasi, Universitas Budi Luhur \\ ${ }^{1,2} \mathrm{Jl}$. Raya Ciledug, Petukangan Utara, Kebayoran Lama, Jakarta Selatan 12260 \\ E-mail : 1412510834@student.budiluhur.ac.id ${ }^{1)}$, lauw.lihin@budiluhur.ac.id ${ }^{2}{ }^{2}$
}

\begin{abstract}
Abstrak
Tujuan penelitian ini adalah membuat sebuah sistem informasi berbasis e-commerce pada Morning Chocolate yang bertujuan untuk membantu dalam peningkatan penjualan supaya mempunyai sistem pemesanan dan penjualan secara online, serta memberikan informasi terbaru tentang produk, harga, kepada pelanggan melalui website. Hasil yang dicapai adalah pembuatan sistem e-commerce membutuhkan sistem penjualan berbasis online. Dalam pengelolaan data seperti update data, edit data dapat dilakukan menjadi lebih mudah. Serta dalam bersaing dengan toko lain, akan semakin percaya diri karena telah memiliki website sendiri. Kesimpulan dalam penelitian ini adalah untuk mempermudah dalam mengelola pesanan yang terabaikan dan juga untuk menghemat waktu dan biaya agar pelanggan tidak perlu datang ke toko untuk berbelanja.
\end{abstract}

Kata kunci: E-Commerce, Internet, Pemesanan, Penjualan.

\section{PENDAHULUAN}

Seiring perkembangan teknologi, kebutuhan akan sebuah sistem informasi sangat dibutuhkan dalam dunia kerja. Manfaat sistem informasi adalah sebagai pendukung operasional pekerjaan. Sistem informasi yang baik adalah sebuah sistem informasi yang mampu bekerja secara akurat, efektif, dan efisien.

Persaingan usaha makanan yang semakin ketat, membuat usaha-usaha sejenis selalu meningkatkan diri agar eksistensi dapat dipertahankan. Kemenangan dalam persaingan tidak hanya bergantung pada modal yang besar, namun juga kecepatan dalam menyediakan informasi yang dibutuhkan.

Seperti halnya pada Morning Chocolate yang merupakan usaha yang bergerak di bidang penjualan snack. Produk yang dijual oleh Morning Chocolate bervariasi, mulai dari yang lokal sampai import. Tersedia berbagai macam produk seperti selai coklat, susu, mie instan, kue kering, dan snack lainnya.

Sistem penjualan yang digunakan di Morning Chocolate saat ini memanfaatkan penggunaan sosial media seperti facebook, instagram, tokopedia. Karena belum memiliki website e-commerce sendiri sehingga masih sangat sulit untuk mempromosikan dan memasarkan produk ke banyak pelanggan, karena pelanggan tidak memiliki cukup waktu untuk datang berkunjung ke toko Morning Chocolate. Dan juga banyak pesanan yang terabaikan jika berjualan melalui sosial media, karena jarang mengecek pesan yang masuk ataupun tidak terus menerus membuka sosial media tersebut, serta kurang efektif karena sosial media lebih mengarah ke tujuan pribadi seperti upload foto sendiri dibanding berjualan.
Jika tidak memiliki website, suatu bidang usaha akan terasa kurang kompetitif. Pelanggan akan sangat kesulitan mencari informasi tentang keberadaan Morning Chocolate dan berbagai jenis produk yang dijual yang tentunya mengakibatkan usaha kurang dikenal dan diminati oleh banyak orang.

Solusi yang diajukan untuk mengatasi masalah Morning Chocolate untuk mengembangkan bisnis penjualannya yaitu adalah dengan penerapan $e$ commerce. E-Commerce merupakan suatu wadah dalam membantu transaksi perdagangan antara penjual dan pembeli melalui internet. Keuntungan yang didapat adalah dapat meningkatkan penghasilan dengan menggunakan metode penjualan online. E-Commerce juga dapat diartikan sebagai pemasangan iklan, penjualan, dukungan, dan pelayanan yang baik dalam sebuah toko online selama 24 jam sehari untuk seluruh pelanggan[1].

Berdasarkan fakta-fakta di atas maka penulis melakukan penelitian lebih lanjut untuk menganalisa sistem yang berjalan dan mengusulkan suatu rancangan sistem informasi yang lebih baik bagi perusahaan. Penulis memilih judul "Sistem Infomasi Penjualan Snack Berbasis E-Commerce Pada Toko Morning Chocolate”.

Berdasarkan hasil analisa dan riset serta pengumpulan data yang dilakukan penulis, permasalahan yang ada pada Morning Chocolate adalah sebagai berikut:

a. Omset penjualan menurun setiap bulan, karena pelanggan sulit untuk memesan produk dan ragu dengan kualitas penjualan lewat sosial media.

b. Banyak pesanan yang terabaikan, karena jarang mengecek pesan di sosial media 
terus menerus atau jarang membuka sosial media tersebut.

c. Banyak saingan jika berjualan di sosial media seperti facebook atau instagram, seperti banyaknya toko-toko online yang membuat akun untuk berjualan, mendapatkan followers yang lebih banyak dari toko kita, sehingga pelanggan akan lebih percaya kepada akun jualan yang memiliki jumlah followers yang lebih banyak.

d. Penjualan di sosial media kurang meyakinkan, karena penggunaan sosial media lebih ditujukan untuk penggunaan pribadi dibandingkan untuk berjualan.

Adapun tujuan dari penulisan ini, sebagai berikut:

a. Membuat sistem usulan penjualan online yang bertujuan untuk menambah jumlah pelanggan yang ada, serta penjualan dapat dilakukan oleh siapapun, kapanpun, dan dimanpun.

b. Membuat sistem usulan data produk yang bertujuan agar pelanggan bisa mengetahui produk apa saja yang dijual oleh Morning Chocolate.

c. Membuat sistem usulan laporan penjualan produk yang sudah dipesan oleh pelanggan yang bertujuan untuk mempermudah staff admin dalam pembuatan laporan. berikut:

Adapun manfaat dari penulisan ini, sebagai

a. Memberikan kemudahan dan kecepatan informasi kepada pelanggan tentang produk yang dijual oleh Morning Chocolate.

b. Membantu Morning Chocolate dalam mempromosikan dan menjual produk kepada konsumen.

c. Memberikan kemudahan dalam mempublikasi informasi, pengolahan data transaksi serta pembuatan laporan.

d. Membangun website e-commerce penjualan snack di Morning Chocolate.

Dalam pembuatan website e-commerce pada Morning Chocolate terdapat dua macam tampilan halaman, yaitu front end atau halaman depan untuk user menjelajahi website, seperti login member, daftar member, serta pemesanan produk dan back end atau halaman belakang untuk admin dalam mengedit pemesanan, produk, kategori, mencetak laporan, dan lainnya.

Batasan masalah yang akan dikerjakan pada Sistem Informasi berbasis e-commerce pada Morning Chocolate adalah sebagai berikut:

a. Proses Pendaftaran Pelanggan.

b. Proses Pemesanan Produk.

c. Proses Pembayaran. d. Proses Pengiriman.

e. Proses Pembuatan Laporan.

\section{METODE PENELITIAN}

Dalam melakukan penelitian ini, penulis menggunakan metode penelitian yang dijelaskan pada gambar 1 berikut ini:

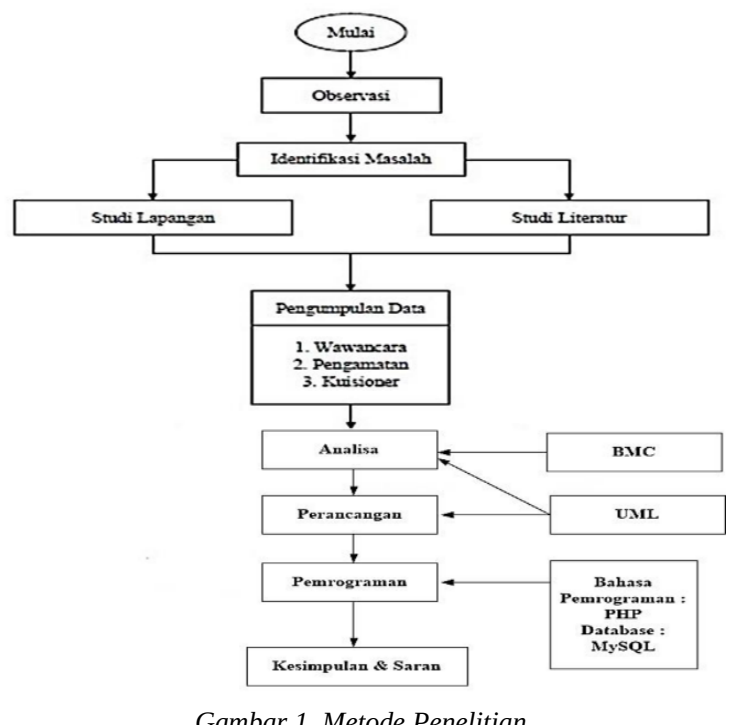

\subsection{Kebutuhan}

Untuk mengetahui kebutuhan yang dipakai, digunakan beberapa teknik atau metode, diantaranya wawancara dengan memberikan pertanyaan kepada pemilik toko Morning Chocolate, Observasi yaitu mengumpulkan data atau dokumen terkait melalui pengamatan lingkungan kerja, dan metode kepustakaan sebagai teknik pengumpulan data dalam penelitian dan membuat Business Model Canvas.

\subsection{Perancangan Sistem}

Dalam melakukan perancangan sistem, peneliti menggunakan Unified Modeling Language (UML), yang terdiri dari Activity Diagram, Use Case Diagram, Class Diagram, dan System Sequence Diagram[2].

\subsection{Pemrograman}

Dalam tahap pemrograman, peneliti menggunakan bahasa pemrograman PHP versi 7 dengan tanpa framework dan bootstrap untuk pembuatan program, serta MySQL sebagai penyimpanan database[3].

\subsection{Pengujian}

Dalam bagian pengujian, peneliti memakai metode black box testing. Black box testing adalah 
metode perancangan yang didasarkan pada spesifikasi perangkat lunak. Data di eksekusi pada perangkat lunak dan kemudia keluaran dari perangkat lunak di uji apakah sudah sesuai dengan yang diharapkan[4].

\subsection{Implementasi}

Setelah berbagai tahapan yang sudah dilakukan dan mengetahui apakah sistem berjalan dengan baik, peneliti menerapkan sistem yang sudah dibuat dan di uji pada toko Morning Chocolate.

\section{HASIL DAN PEMBAHASAN}

\subsection{Business Model Canvas}

Business Model Canvas adalah penjelasan mengenai konsep dasar pemikiran bagaimana sebuah bisnis diciptakan, diberikan, dan ditangkap nilainya. Dalam pembangunan sistem E-Commerce, peneliti menggunakan model Business Model Canvas untuk merancang kerangka kerja serta menganalisa masalah-masalah dan kebutuhan yang ada pada toko Morning Chocolate. Tujuan dari penelitian ini yaitu untuk mengetahui rancangan alur proses pembangunan website E-Commerce pada toko morning chocolate dan strategi bisnis yang tepat, seperti yang dijelaskan pada gambar 2 berikut ini[5]:
Gambar 2. Business Model Canvas Template by Alexander Osterwalder

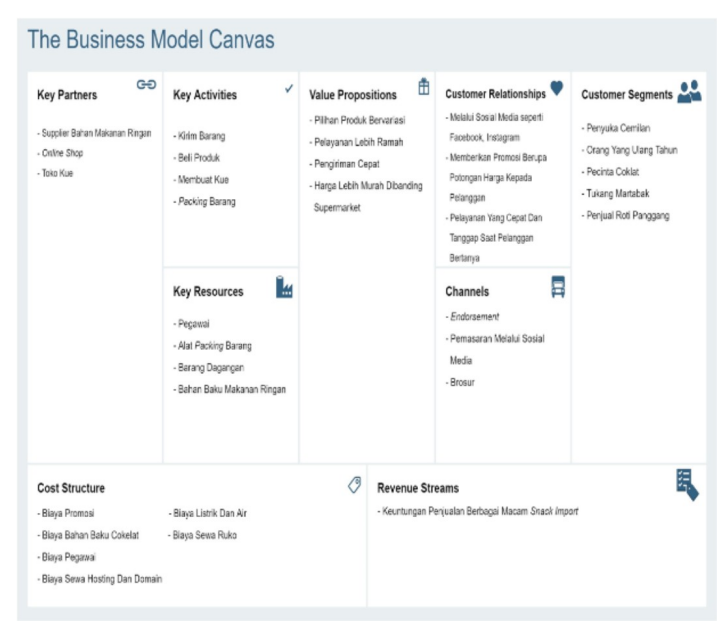

\subsection{Activity Diagram}

Activity Diagram adalah sebuah cara memodelkan event-event yang terjadi dalam suatu use case. Berikut merupakan proses bisnis dan activity diagram usulan yang dibuat peneliti untuk toko Morning Chocolate:

a. Proses Pendaftaran

Pelanggan harus mendaftar di web Morning Chocolate. Caranya dengan klik tombol Register/Login lalu lengkapi data-data pada form Pendaftaran. Lalu setelah itu pelanggan akan menerima email aktivasi untuk akun, dan pelanggan bisa mengaktivasi akun lewat email yang dikirim oleh sistem, seperti yang dijelaskan pada gambar 3 berikut ini: 


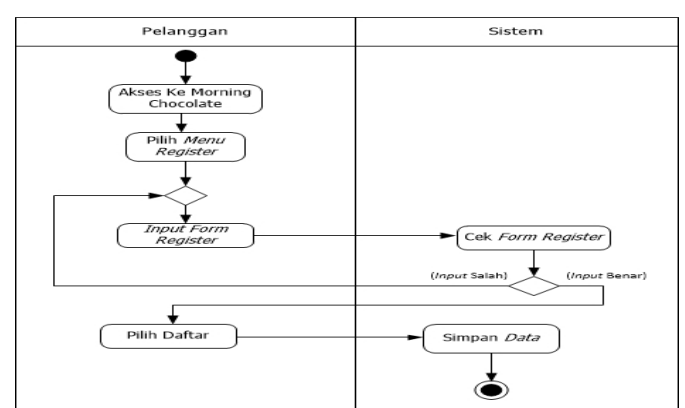

Gambar 3. Activity Diagram Proses Pendaftaran Member

b. Proses Pemesanan

Pelanggan harus login terlebih dahulu sebelum membeli produk. Pelanggan dapat memilih produk sesuai kategori atau memilih langsung produk yang akan dibeli. Produk yang sudah dipilih akan masuk ke dalam Keranjang Belanja, lalu pelanggan memasukkan jumlah produk yang diinginkan. Jika pelanggan ingin melanjutkan belanja, pelanggan bisa memilih lanjutkan belanja, jika tidak pelanggan bisa memilih selesaikan belanja. Lalu setelah itu pelanggan akan dibawa ke halaman konfirmasi pesanan kemana pesanan produk akan dikirim. Setelah pemesanan selesai, barang akan masuk ke daftar Transaksi Pesan, seperti yang dijelaskan pada gambar 4 berikut ini:

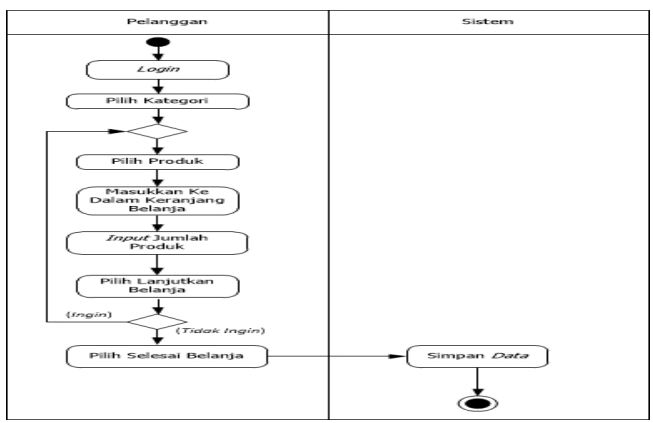

Gambar 4. Activity Diagram Proses Pemesanan Produk

c. Proses Pembayaran

Pelanggan dapat melakukan pembayaran dengan cara transfer ke rekening Morning Chocolate. Setelah pelanggan melakukan pembayaran, pelanggan dapat melakukan Konfirmasi Pembayaran. Konfirmasi Pembayaran dilakukan dengan cara pelanggan menginput data pembayaran dan mengirim gambar bukti pembayaran lalu sistem akan menyimpan data dengan otomatis. Jika pembayaran valid admin akan mengkonfirmasi pembayaran dan pesanan siap dikirim ke alamat pelanggan, seperti yang dijelaskan pada gambar 5 berikut ini:

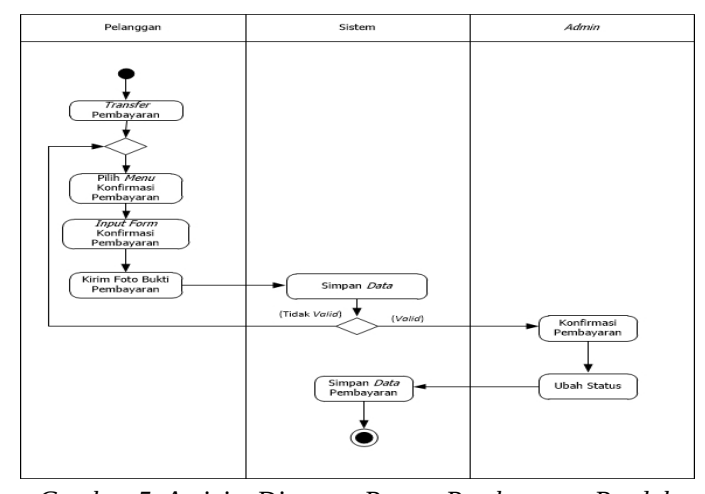

Gambar 5. Activity Diagram Proses Pembayaran Produk

\section{d. Proses Pengiriman}

Admin memilih menu pengiriman kemudian admin menginput resi dan sistem akan menyimpan data. Kemudian admin akan mengupdate resi pelanggan pada menu resi, setelah itu sistem akan menyimpan data resi yang bisa dilihat pelanggan, seperti yang dijelaskan pada gambar 6 berikut ini:

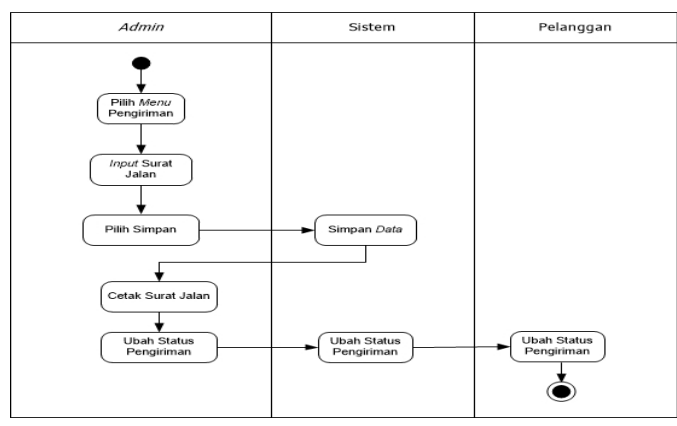

Gambar 6. Activity Diagram Proses Pengiriman Produk

e. Proses Pembuatan Laporan

Admin akan membuat laporan kepada pemilik toko tentang laporan pemesanan, laporan pembayaran, laporan pengiriman, laporan produk terlaris, laporan stok produk, dan laporan data pelanggan, seperti yang dijelaskan pada gambar 7 berikut ini:

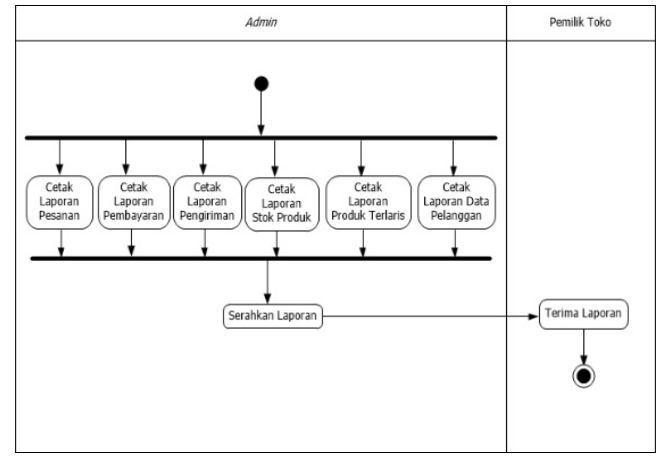

Gambar 7. Activity Diagram Proses Pembuatan Laporan 


\subsection{Use Case Diagram}

Use Case adalah adalah deksripsi fungsi dari sebuah sistem dari perspektif pengguna. Use Case bekerja dengan cara mendeskripsikan tipikal interaksi antara pengguna sebuah sistem (aktor) dengan sistemnya sendiri melalui sebuah cerita bagaimana sebuah sistem dipakai. Berikut adalah Use Case Diagram seperti yang dijelaskan pada gambar 8, gambar 9, gambar 10, dan gambar 11 berikut ini:

a. Use Case Diagram Master

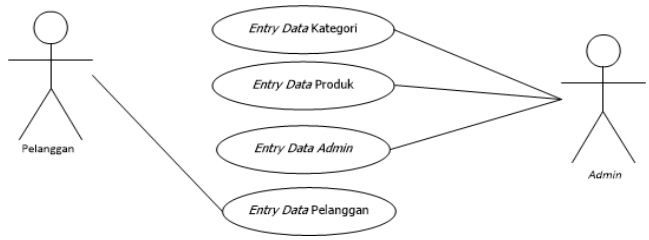

Gambar 8. Use Case Diagram Master

b. Use Case Diagram Transaksi Pelanggan

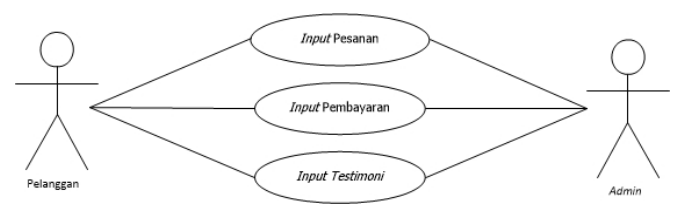

Gambar 9. Use Case Diagram Transaksi Pelanggan

c. Use Case Diagram Transaksi Admin

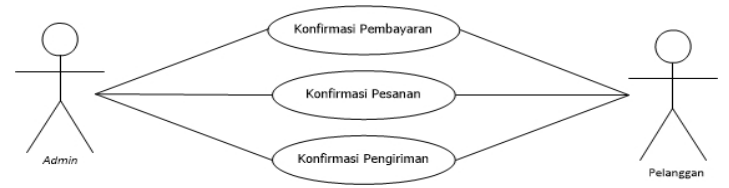

Gambar 10. Use Case Diagram Transaksi Admin

d. Use Case Diagram Laporan

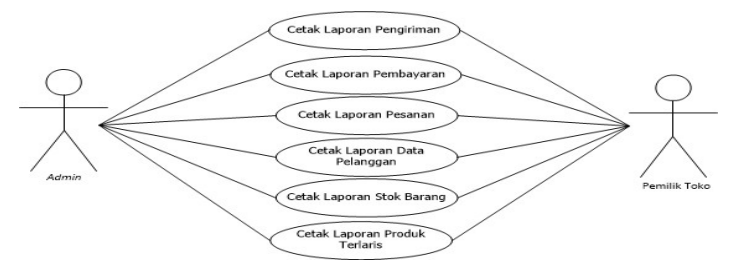

Gambar 11. Use Case Diagram Laporan

\subsection{Class Diagram}

Berikut ini adalah Class Diagram seperti yang dijelaskan pada gambar 12 berikut ini:

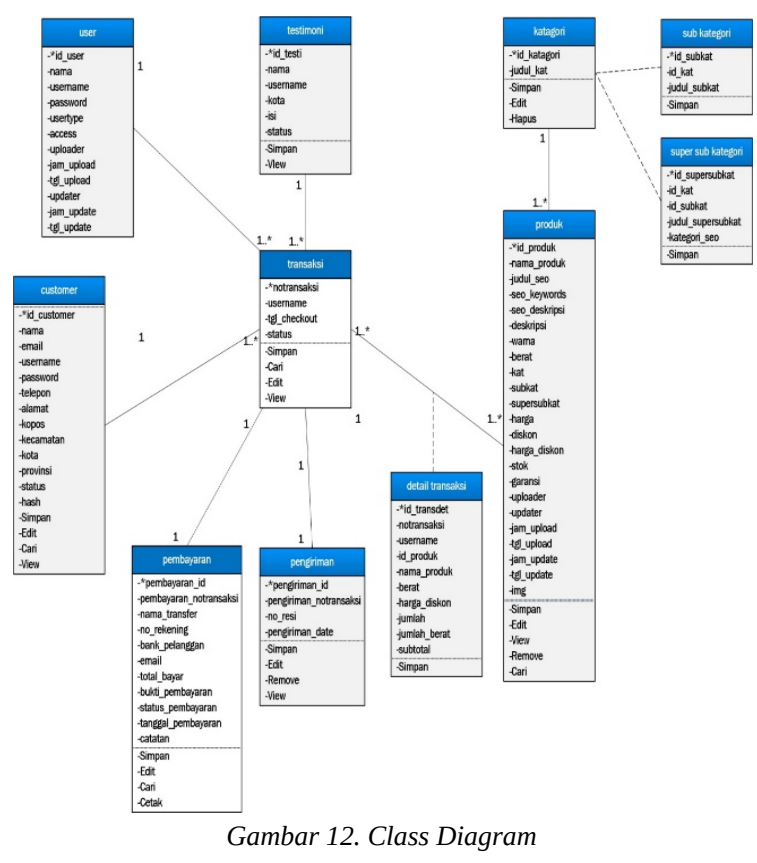

\subsection{Struktur Tampilan (Menu)}

Berikut ini adalah struktur tampilan menu admin pada Toko Morning Chocolate, seperti yang dijelaskan pada gambar 13 berikut ini:

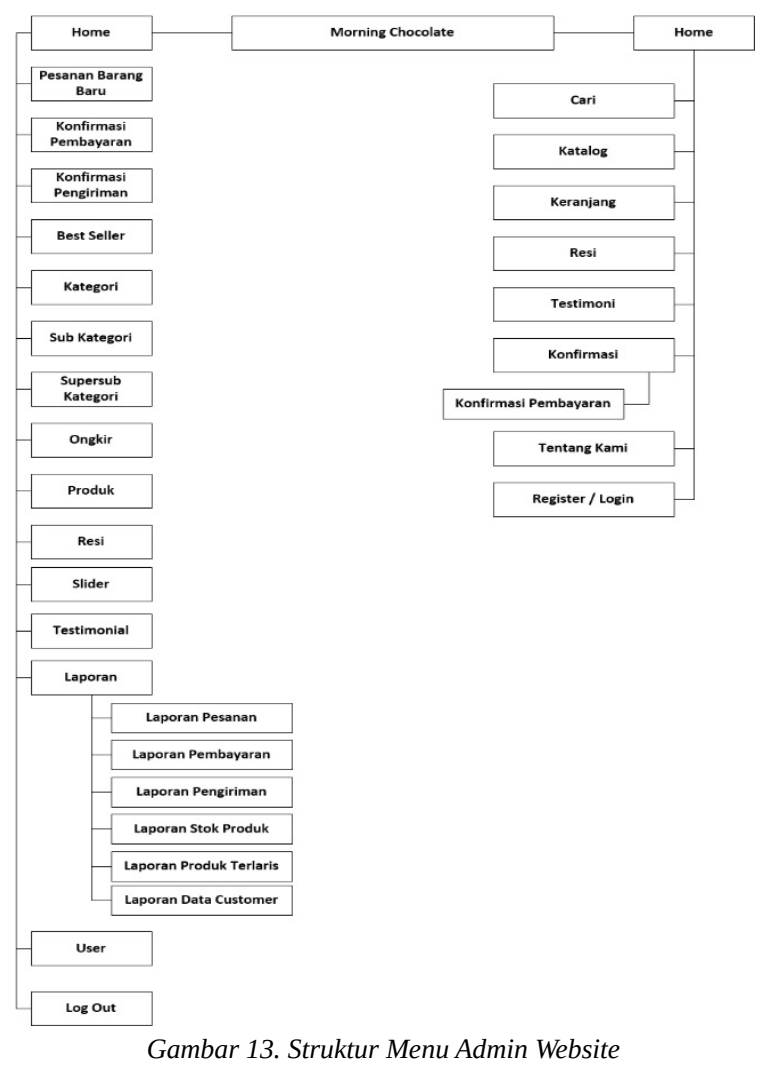




\subsection{Rancangan Layar}

a. Halaman Depan

Berikut adalah rancangan layar beranda sebelum login pada website morningchocolate.id, seperti yang dijelaskan pada gambar 14 berikut ini:

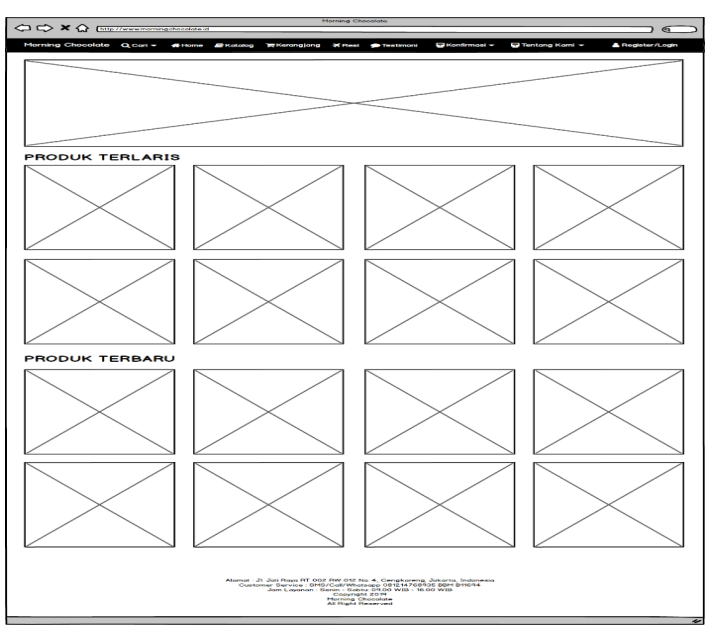

Gambar 14. Tampilan Halaman Depan Website

b. Login

Berikut ini adalah rancangan layar login akun pada toko Morning Chocolate, seperti yang dijelaskan pada gambar 15 berikut ini:

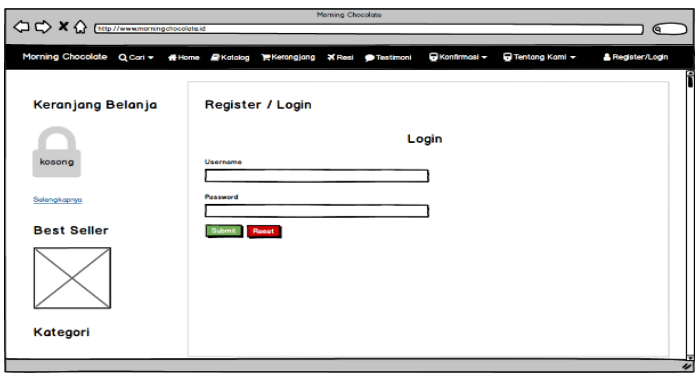

Gambar 15. Tampilan Halaman Login Website

c. Register

Berikut ini adalah rancangan layar register akun pada toko Morning Chocolate, seperti yang dijelaskan pada gambar 16 berikut ini:

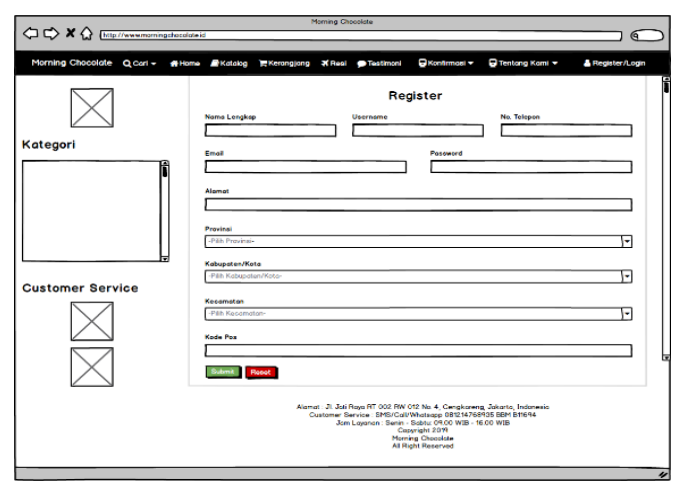

Gambar 16. Tampilan Halaman Register Website d. Keranjang Belanja

Berikut ini adalah rancangan layar keranjang belanja pada toko Morning Chocolate, seperti yang dijelaskan pada gambar 17 berikut ini:

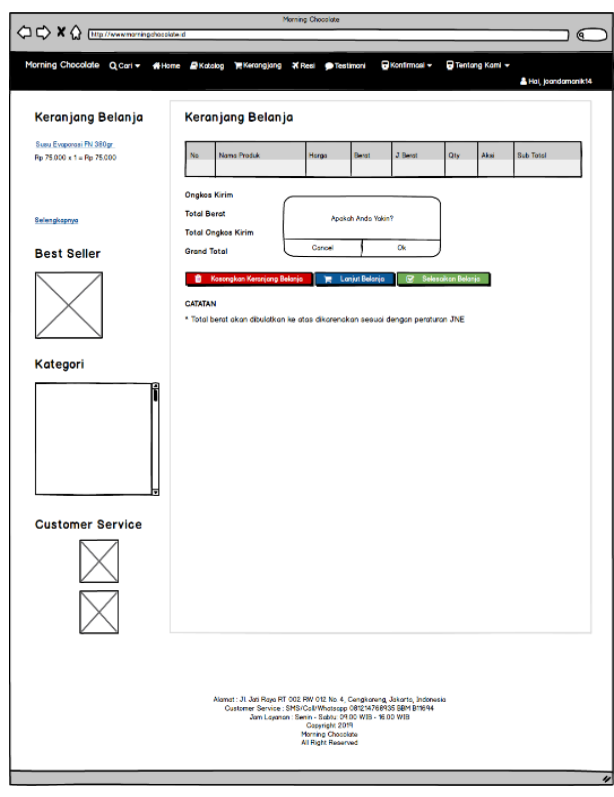

Gambar 17. Tampilan Halaman Keranjang Belanja

e. Konfirmasi Pembayaran

Berikut ini adalah rancangan layar untuk konfirmasi pembayaran, seperti yang dijelaskan pada gambar 18 berikut ini:

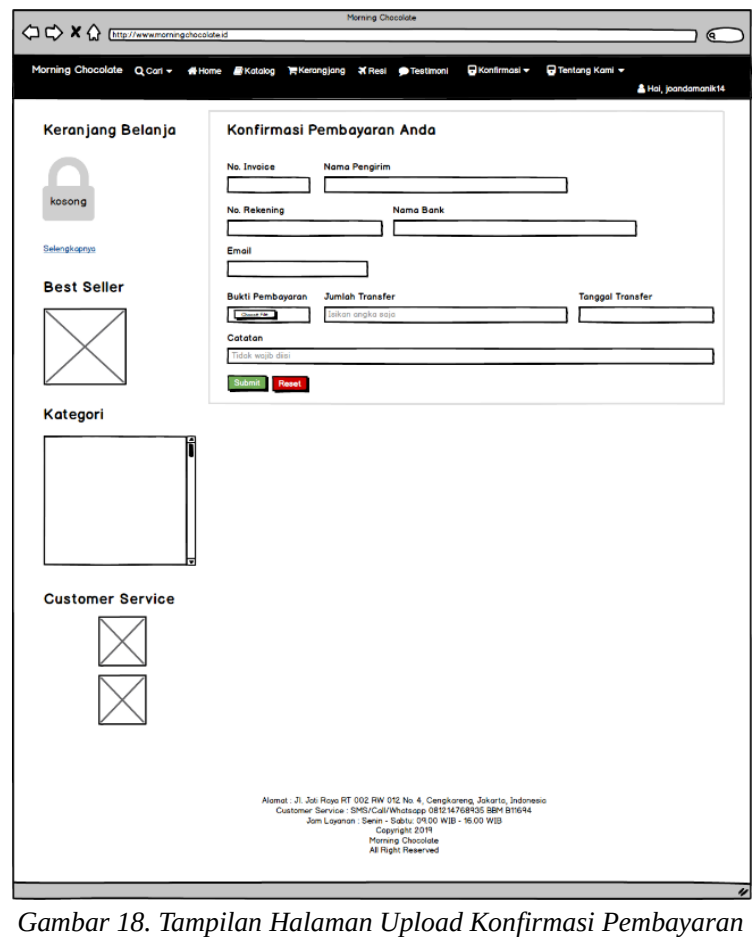

Gambar 18. Tampilan Halaman Upload Konfirmasi Pembayaran 


\subsection{System Sequence Diagram}

System Sequence Diagram terbentuk oleh activity diagram dan class diagram. System Sequence Diagram melambangkan aliran pesan yang terbentuk antar kelas pada class diagram dengan menggunakan metode yang dimiliki kelas tersebut. Berikut adalah system sequence diagram yang digambarkan peneliti pada toko Morning Chocolate, seperti yang dijelaskan pada gambar 19, gambar 20, gambar 21, gambar 22, dan gambar 23 berikut ini:

a. System Sequence Diagram Registrasi

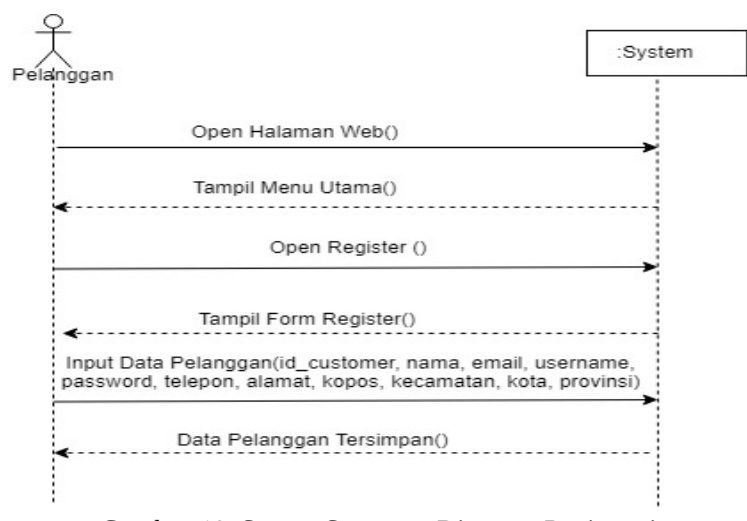

Gambar 19. System Sequence Diagram Registrasi

b. System Sequence Diagram Entry Data Pesanan

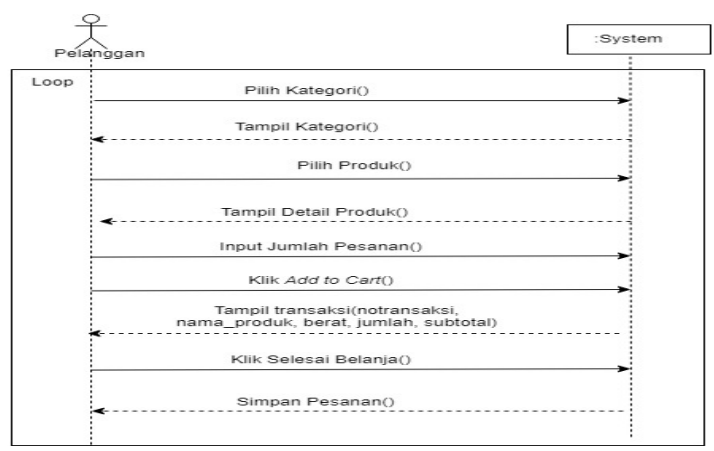

Gambar 20. System Sequence Diagram Entry Data Pesanan

c. System Sequence Diagram Entry Data Pelanggan

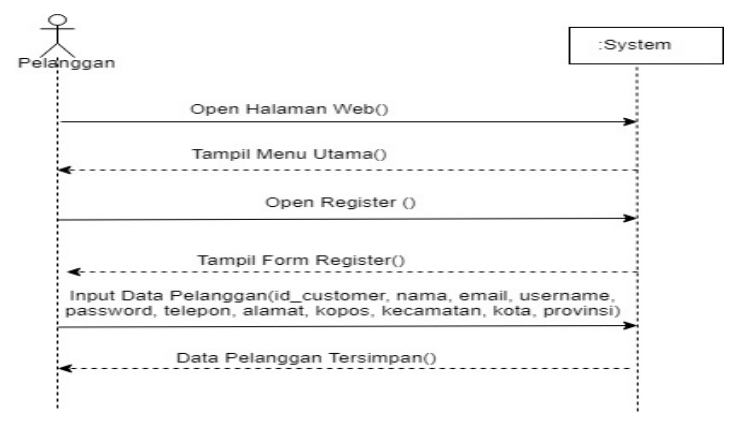

Gambar 21. System Sequence Diagram Entry Data Pelanggan d. System Sequence Diagram Konfirmasi Pembayaran

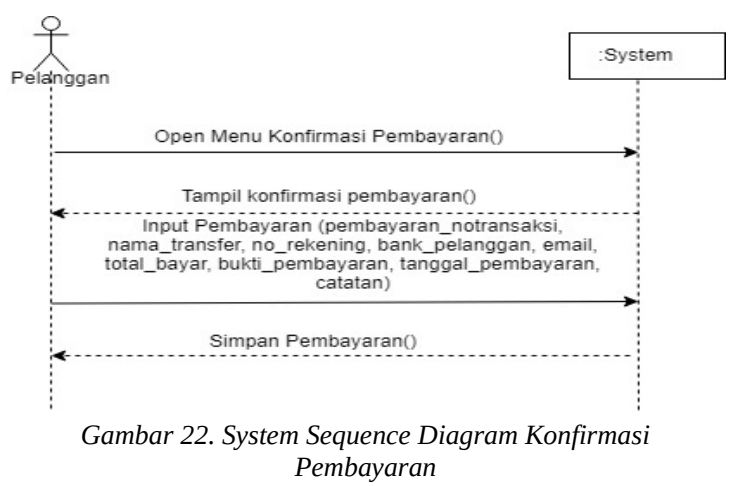

e. System Sequence Entry Laporan Pesanan

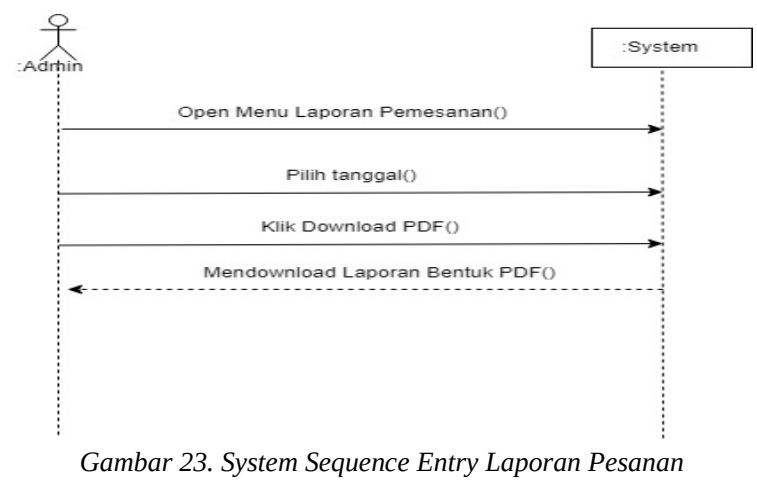

4. KESIMPULAN

Dari uraian tentang Sistem Informasi Penjualan Snack berbasis e-commerce yang telah dibahas pada bab sebelumnya, kesimpulan yang diberikan penulis adalah sebagai berikut:

a. Omset yang menurun akan jadi meningkat, karena pelanggan tidak akan ragu lagi untuk berbelanja di website, dengan adanya fitur testimoni akan menjamin kualitas produk akan terjaga.

b. Masalah pesanan yang terabaikan akan berkurang dengan adanya fitur e-commerce sehingga membuat penjual selalu bisa mengontrol penjualannya denga mudah.

c. Persaingan yang dihadapi akan menjadi lebih mudah dan semakin percaya diri, karena tidak perlu jumlah followers yang banyak untuk menentukan jumlah pembeli, melainkan kualitas produk dan testimoni yang akan jadi acuan.

d. Tidak perlu lagi berjualan di sosial media, karena dengan adanya e-commerce, semua sistem penjualan akan menjadi lebih mudah. 


\section{DAFTAR PUSTAKA}

[1] Ridwan dan Wisnu, Membangun Kerajaan Bisnis Online, Jakarta: Kompas Gramedia, 2009.

[2] Gata, W. dan Grace, G, Sukses Membangun Aplikasi Penjualan dengan Java, Jakarta: Elex Media, 2013.

[3] Andi, Aplikasi Web dengan PHP dan MySQL, Jakarta, 2016.

[4] Rosa, A. S. dan Shalahuddin, M, Rekayasa Perangkat Lunak Terseruktur, Bandung, 2015.

[5] Osterwalder, A and Pigneur, Y, Business Model Generation : A Handbook for Visionaries, New Jersey, John Wiley \& Sons, Inc, 2010. 